\title{
Opening the Black Box of Intellectual Autonomy
}

\author{
Thomas Medvetz \\ University of California, San Diego \\ tmedvetz@ucsd.edu
}

Michèle Lamont's How Professors Think is a compelling, nuanced, and richly observed empirical study of the inner workings of academic peer review panels - the forums convened by major funding agencies to assess research grant and fellowship proposals. Based on more than eighty recorded interviews with panelists from five organizations and extensive firsthand observations of three interdisciplinary panels, the book offers major insights into the "evaluative cultures" of academic disciplines in the United States and, more broadly, the construction of scholarly excellence. As academic gatekeepers, Lamont argues, the members of peer review panels collectively play a pivotal role in the distribution of material and symbolic rewards within the U.S. university system.

At a different level, How Professors Think can be read as an entry into the ongoing project of developing a sociological theory of action, especially one that takes into account the complex relationship between its two main generative aspects: practical sense and theoretical reason. Although Lamont often refers to principles of scholarly evaluation as criteria (a term that suggests relatively codified decision-making standards), she also pays close attention to the ephemeral, "emotional," and fuzzy elements of scholarly judgment. Indeed, it is striking how many of the "evanescent" decision-making factors Lamont and her respondents refer to make use of the term sense (among others, "shared sense," "common sense," and "sense of self"). This focus on the practical sense of peer reviewers allows Lamont to avoid representing scholarly excellence either as an immutable or transcendental "essence," entirely objective or impervious to socio-historical forces. Yet neither does Lamont depict academic evaluation as a simple product of academic status struggles. Instead, How Professors Think develops a sophisticated theory of scholarly judgment as a mode of collective problem-solving that obeys a set of rules specific to the academic sphere. At various points, the book also offers useful insights into the contrasting styles and "epistemic cultures" of six academic disciplines. 
In reacting to a study as rich and thoughtful as this book, I find it necessary to focus my comments on a central question: What can How Professors Think teach us about the cognitive autonomy of U.S. scholars, that is to say, about their collective ability to "insulate [themselves] from external forces," especially those originating in the political and economic fields, and "uphold [their] own criteria of evaluation over and against those of neighboring or intruding fields"? (Wacquant 2007: 269) If this concern narrows the terms of the discussion on the one hand, then on the other hand it widens them considerably. After all, to address the question will require lifting Lamont's empirical observations out of the specific institutional context in which they were made and considering academic peer review panels in comparative perspective. In keeping with the request of the symposium editors, I will orient my comments to the "similarities and differences between the panels of experts" in Lamont's study and the world of public policy "think tanks" - the loosely bounded network of organizations that have become fixtures of U.S. politics since the 1970s, even as they have proliferated around the world, including within Spanish politics (see, for example, Freres et al. 2000; McGann 2012; Medvetz 2012).

What is the effect of resituating Lamont's argument within the wider social ecology of knowledge production in the United States? My answer has two parts. First, I will argue that this approach allows for a new appreciation of How Professors Think that has gone largely unremarked, even within the considerable body of writing that has already emerged in response to it (see the editors' introduction). In particular, the book contains valuable resources for sociologists who wish to grasp the notion of cognitive autonomy and apply it to the empirical study of intellectuals. Second, I will argue that the book's chief limitation lies in its relatively narrow empirical focus, which gives rise to a stance that-while remaining free of epistemological relativism-leads to an analytic relativism that insists on giving equal pride of place to both the limits and reach of cognitive autonomy. By placing the academic peer review panels of Lamont's study within the wider social ecology of knowledge production, we can sketch the broad contours of a more comprehensive view that highlights the relative autonomy of academic peer reviewers and the relative heteronomy of policy experts, currently their chief rivals in the struggle over policy relevant knowledge.

How does the practice of academic peer review as Lamont describes it compare to policy research - the term I will use to refer to the practical routines and repertoires that prevail in the nebulous world of think tanks? The first clear difference is that among think tanks, peer review itself is almost entirely absent. Most policy experts freely publish "policy briefs," reports, blog postings, and other written products without submitting them to a peer review system. Furthermore, numerous key products of policy research are not written materials at all, but rather speeches, briefings, panel discussions, congressional testimony, 
and television and radio punditry. However, rather than drawing any hasty conclusions from this difference, let us consider the most notable similarities between the practical logics of peer review and policy research.

In the first place, it should come as no surprise that in neither setting can judgments of excellence be plausibly described as the result of a purely mental or cognitive process. Furthermore, both modes of judgment are inevitably shaped by forces external to the institutional setting itself, including considerations of the most banal and prosaic sorts. Lamont cites several factors that fall outside of official, codified definitions of scholarly merit but condition the peer review process, including reviewers' perceptions of applicants' personal virtues and the time limits built into the evaluation process. Moreover, the same panelists sometimes make decisions in Potter Stewart-esque fashion, ${ }^{1}$ by using criteria that never rise to the level of consciousness. Likewise, as I will elaborate below, policy researchers inevitably bring factors originating outside of the world of think tanks to bear on the process of judging policy research. For the moment, however, the notable point is that in neither setting can excellence be represented in terms of a pure "essence" or as a self-evident feature of the intellectual product.

Notwithstanding the uncertainty and fuzziness that sometimes characterize the act of judging excellence in both settings (especially where encounters among structurally distant actors are involved), there is a discernible social order to each setting. Moreover, in both cases, this order emerges largely out of social and interactional dynamics particular to the institutional setting in question. ${ }^{2}$ This is another way of saying that each domain has developed a kind of autonomy. Lamont, for example, describes the specific "rules" of reviewer deliberation, themselves based largely on shared principles of scholarly judgment. Similarly, policy experts obey certain rules specific to think tanks. However, in the next section I will argue that this apparent similarity gives way to a major difference inasmuch as the form of "autonomy" found among think tanks is deeply fraught with paradox and better described as a kind of "hyper-dependence."

Before moving on, a final point of similarity between peer review panels and think tanks is worth noting: the subtle layering of conflict and consensus within each institutional setting. As Lamont shows, peer review panels are pregnant with the potential for disagreement, especially those based on "epis-

1. For readers not familiar with this reference: Potter Stewart (1915-1985) was a U.S. Supreme Court Justice who famously acknowledged, in the context of a 1964 obscenity case, that the concept hard-core pornography defied easy definition, but downplayed the problem by writing that, "I know it when I see it." Stewart's quote is often held up as an exemplar of tautological inference.

2. I use these separate terms, social and interactional, to highlight a distinction between peer review panels and think tanks. In short, whereas the dynamic of peer review is anchored largely in direct interaction, among think tanks, more distant forms of social influence that cannot properly be labeled interactional (including imitation, self-differentiation, and other forms of mutual orientation) supply the chief relational logic. 
temic cultural" differences among disciplines. In the setting of think tanks, conflict and consensus also go hand in hand-political ideology being the most publicly salient axis of conflict, even if organizational competition, including between ideological allies, often eclipses ideology in its importance. Nevertheless, in each setting, an analytic "scale shift" underscores a layer of consensus rooted in the fact that the actors are engaged in a common project. On academic peer review panels, for example, disciplinary pride may induce an economist to take a dim view of a grant application endorsed by a political scientist. Yet if the disagreement rises to the level of open conflict, it is likely to reaffirm certain commonalities in the panelists' criteria of scholarly judgment. In the same way, think tanks compete with one another for money, attention from politicians, and media coverage, even as they collaborate on projects, cultivate extensive network ties, and insist almost unanimously that their work is more "useful" and "tied to the real world" than that of their academic counterparts. In fact, academic scholars constitute the main reference group against which policy experts recognize their affinities.

This last point has major implications for the discussion. What it suggests, above all, is the futility of comparing peer review panelists and policy experts on purely analytic ${ }^{3}$ grounds, or as if the two sets of actors exist in isolation from each other. To adopt this approach would be to reduce the relations among them to relations of similarity and difference when in fact academic peer reviewers and policy experts inhabit the same social space and engage in relations of struggle, hierarchy, and mutual influence. The final section of my contribution will briefly consider the significance of this point and arrive at a general conclusion about How Professors Think.

Should we take the preceding discussion to mean that similarities between academic peer review and policy research outweigh differences? The question, I would submit, is neither trivial nor arcane, yet its answerability turns on whether or not it is possible to defend the utility and coherence of the concept cognitive autonomy. Difficult to grasp, much less to apply empirically, the "problem of autonomy" is one that has hampered the sociology of knowledge and intellectuals since its birth. Moreover, the problem seems neither to have lessened over time nor in relation to the boldness of those who dismiss it. (One thinks of Julien Benda's La Trahison des Clercs, Edward Said's injunction to "Speak truth to power," and Chomsky's castigation of the "new mandarins" - all of which defined the intellectual's proper mission partly in terms of cognitive autonomy and charged a segment of the intelligentsia with a betrayal and yet none of which actually resolved anything in the social scientific study of intellectuals.)

3. I use the word analytic in the sense derived from linguistics, which refers to a morphological category consisting of languages characterized by isolated as opposed to synthetic grammatical elements. 
Faced with the absence of any pure, unvarnished, or absolute concept of cognitive autonomy, one confronts a seemingly stark epistemological choice. One path-plainly the more extreme-is to renounce the concept of autonomy altogether. This is not Lamont's position, nor is it mine, but one of its effects is worth noting here. Without even reverting to a philosophical argument against epistemological relativism, I would simply note the practical "finality" of any such stance. Just as the last move in a chess match means that the game is over-even for the winner-a tenable defense of epistemological relativism leaves only one non-disingenuous move for the defender: namely, walk away and remain silent. ${ }^{4}$ I would also note, in defending the need for an analytic conception of cognitive autonomy, the idea's resonance in everyday speech, which is greater than commonly acknowledged. To say that a given statement is biased, partisan, or self-interested, for example, is tantamount to saying that its truth-value is wanting because the thinking underpinning it has met with some sort of encumbrance along the way. The encumbrance may be the result of direct coercion or it may be linked more distantly to habit, self-interest, adherence to an ideological program, loyalty to a national or religious culture, or some combination of these. It does not matter: the point is that the everyday coherence and self-resonance of truthclaims generally rest on an implied background notion akin to cognitive autonomy.

What this discussion suggests to me is the need to fortify a conception of cognitive autonomy rooted in intellectual practices and relations. Among sociologists, the best approach has been offered by sociologists who insist on rescuing the idea of cognitive autonomy from its "theoreticist" confinement by assigning it these features:

(i) Social. On this view, cognitive autonomy is a property that obtains at the level of the group and depends on a notion akin to epistemic culture. Just as it is nonsensical to speak of a private language or culture, in other words, we can posit the impossibility of a private or individual autonomy;

(ii) Generative. As opposed to mere freedom from constraint, cognitive autonomy must be understood in terms of positive commitment or duty with respect to an epistemic culture. In this sense, the Kantian notion of freedom as obedience to a self-imposed rule supplies a useful analogy;

(iii) Conditional. To reiterate a point made earlier, there is no such thing as cognitive autonomy in any pure or absolute sense; any claim about a group's autonomy therefore implies some kind of comparison or contextual description.

4. It is difficult to raise this point without also mentioning Lamont's (1987) classic piece about Jacques Derrida's intellectual career. He did not walk away or remain silent, but the latter stage of his career seems to reaffirm my central point, albeit in a different sense. As many scholars have argued, Derrida was compelled to invent ever more elaborate ways of saying, in effect, that there was no stable truth to express. 
Among social theorists who might be identified with the view of cognitive autonomy I am suggesting here, Bourdieu is likely the most prominent contemporary thinker; however, the idea's long pedigree extends at least to Weber's claims about the disaggregation of modern societies into autonomous and incompatible value spheres.

Drawing on a notion of cognitive autonomy as a social, generative, and conditional property, I would argue that the differences between think tanks and academic peer review panels vastly outweigh the similarities. As noted above, few think tank-affiliated policy experts must subject themselves to the judgments of peers who enforce positive standards of intellectual rigor. Furthermore, insofar as think tanks collectively acquire a form of autonomy, it is a peculiar one built on an elaborate balancing act or game of separation and attachment vis-à-vis other, more established fields-especially those of academic, political, economic, and media production. Insofar as think tanks align themselves with the world of scholarly production, they tend to do so in a temporary and superficial manner, in order to capture a dose of academic authority without accruing any of the dishonors associated with the image of the "ivory tower." Too much scholasticism impedes their pursuit of political relevance, funding, and publicity. Although in their public self-descriptions policy experts often emphasize the idea of scholarly rigor (or, in the words of one think tank, a single-minded "commitment to...reason and facts"), the most significant rewards generally flow to those who can skillfully balance the contradictory styles of the policy aide, the lobbyist, the public relations guru, the political consultant, the entrepreneur, and, to some degree, the academic scholar (Medvetz 2010). This means that the following qualities can all significantly enhance a policy expert's reputation: a knack for making memorable quips, sound bites, and slogans; willingness to engage in the rapid-fire production of policy briefs and memos (often in reaction to still-developing news stories); the ability to predict which policy issues will become "hot" in the near future; being "good on television"; and, perhaps most important, establishing rapport with donors. ${ }^{5}$

Elsewhere I have argued that "the search for the totally unencumbered intellectual is a futile one, since all intellectuals-from the college professor who must 'publish or perish' to the technocrat who cannot challenge the basic premises of her research assignment-face certain necessities and constraints in their work" (Medvetz 2012: 153). The inverse point is equally significant: "the language of pure determination is troublesome as well, since even if inte-

5. In an interview, Norm Ornstein, a fellow at the American Enterprise Institute whom The Washington Monthly once dubbed the "king of quotes" for his prodigiousness in supplying sound bites to American journalists, told me with notable pride that editors at the Los Angeles Times - having reached the conclusion that their newspaper had grown too dependent on Ornstein quotes-issued an explicit moratorium on statements from the policy expert. It seems likely that Ornstein could experience this episode as a "victory," even though its result was an enforced (albeit circumscribed) form of invisibility, precisely because it exposed a weakness in the journalistic field itself. 
llectuals are always constrained in some way, they are inevitably motivated by certain positive ambitions, drives, and desires." (Ibid.). Put differently, opening the black box of cognitive autonomy requires describing these positive ambitions, drives, and desires in practical and social terms, which rest on the presence of communities of relatively like-minded thinkers who tacitly or explicitly possess what Lamont calls "shared definitions of quality". This is precisely what I believe How Professors Think does so well.

My only quarrel with the book lies in its occasional tendency to revert to a purely philosophical notion of cognitive autonomy through the reflex of giving equal weight to autonomy's limits and reach. Widening the analytic lens slightly beyond the world of academic peer review leads to a different emphasis. After all, when situated in the broader intellectual field, the peer review panels Lamont studies become notable for their relatively high self-governing capacities and their stable ties to disciplinary and professional organizations, departmental units, and academic journals. To be sure, How Professors Think also considers the threats to autonomy experienced by two academic disciplines in which the "problem of the boundary" is posed somewhat acutely: namely, anthropology and English literary studies. However, I would submit that such threats are the norm rather than the exception - and that a proper sociology of knowledge and intellectuals must proceed from the Nietzschean maxim that those "who leave every glass standing only half-emptied refuse to admit that everything in the world has its sediments and dregs." Put differently, opening the black box of autonomy inevitably reveals "sediments and dregs." Thus, to emphasize the absence of pure cognitive freedom in the name of "moderation" is to risk honoring the sort of mediocrity to which the same writer referred in the following terms: "Virtue for them is what maketh modest and tame... That, however-is mediocrity though it be called moderation."

\section{Bibliographic References}

Freres, Christian; Seabra, Maria Joao and Moraes, Maria do Rosario (2000). "Think Tanks in Spain and Portugal: Searching for Relevance”. In: MCGANN, James G. and R. WeAver, Kent (eds.) Think Tanks \& Civil Societies: Catalysts for Ideas and Action. New Brunswick, NJ: Transaction Publishers. Pp. 187-221.

Lamont, Michèle (1987). "How to Become a Dominant French Philosopher: The Case of Jacques Derrida.” American Journal of Sociology 93(3): 584-622.

McGann, James G. (2012). Global Go To Think Tanks Index Report. Philadelphia, PA: Think Tanks and Civil Societies Program.

Medvetz, Thomas (2010). "Public Policy is Like a Having a Vaudeville Act': Languages of Duty and Difference Among Think Tank-Affiliated Policy Experts." Qualitative Sociology, 33(4), 549-562.

- (2012). Think Tanks in America. Chicago, IL: University of Chicago Press.

WACQUANT, Loïc (2007). "Pierre Bourdieu." In: Stones, Rob (ed.). Key Contemporary Thinkers. London and New York: Palgrave Macmillan. Pp. 261-77. 